\title{
Experimental Study on Seismic Behavior of High Strength Reinforced Concrete Frame Columns with High Axial Pressing Ratio
}

\author{
Guojun ZHANG ${ }^{1, a^{*}}$, Benliang Liang ${ }^{1, b}$, Boquan Liü, c \\ ${ }^{1}$ Architecture Engineering College, Shanghai Normal University, Shanghai 201418, China \\ ${ }^{2}$ Architecture Engineering College, Chang'an University, Xi'an 710061, China \\ azhgixi@163.com, ${ }^{b}$ lbl@shnu.edu.cn , ${ }^{\mathrm{b}}$ bqliu@chd.edu.cn
}

\begin{abstract}
Keywords: high strength concrete; axial pressing ratio; stirrup ratio; hysteretic properties; ductility. Abstracts: In order to research feasibility of high strength concrete applied to the main factory building frame and framed bent structure of large-scale firepower plant, based on the experimental research of 6 reinforced high strength frame slender columns under frequency cyclic loading, the failure shape and hysteretic characteristics were discussed. The main results show the surface concrete shedding of columns with high axial compression ratio and low hoop rate of the column drop more serious and those of columns with low axial compression ratio and high hoop rate drop slightly; with the decrease of axial compression ratio and stirrup ratio increases, the column hysteretic curve become increasingly full; the cumulative hysteretic energy become more and more big; the absorbed earthquake energy increases; the ductility also increases accordingly; whether high or low strength concrete frame column, with the axial compression ratio increases, the ductility decreases; the ductility of ordinary concrete columns is basically linear relation; the ductility of high strength concrete frame columns decreases nonlinearly with axial compression ratio increases.
\end{abstract}

\section{Introduction}

In practical design, the column section in the large thermal power plant is controlled by the limit values of axial compression ratio and their sectional dimension is usually larger, so it not only increase the structural weight but also occupy space, which effects of structure. High-strength concrete used in the frame-bent structure of large thermal power plant can decrease column section, ease weight and improve the load-bearing capacity of the structure ${ }^{[1-6]}$. Under high axial compression ratio the deformation capacity of high strength concrete column needs more experimental studies to verify. In this paper, the mechanical properties test of 6 high-strength concrete frame columns under frequency cyclic loading were carried out, and then the factors such as the axial load ratio, lateral reinforcement forms and the stirrup ratio which affected the failure shape, hysteretic characteristics and ductility of the components were analyzed.

\section{Experimental Basic Facts}

The Specimen Design. The original models of specimens took from some constructed engineering. The ratio of similitude of model to practical structure is 1:3; the test adopts cantilevered columns according to experience requirement of practical engineering; the sectional dimension took $140 \mathrm{~mm}$ $\times 280 \mathrm{~mm}$; The height of cantilevered column took $1120 \mathrm{~mm}$ and 1400 ; transverse reinforcements took HRB235 heated bundle reinforcing steel; longitudinal reinforcements took HRB335 heated bundle reinforcing steel. The three configurations of stirrups adopted in this test, the specimen size, the design of test parameters and reinforcement detailing see details in literature [5,6].

The Loading Device and System and Arrange of Foil Gage. The loading device and system is as shown in the literature [5,6]. The arrange of foil gage of concrete, stirrup and longitudinal reinforcement as shown in the literature $[5,6]$.

\section{The main test results and analysis}

The description of failure process and the failure form. The cracking loads of columns HC4, 
HC5 and HC6 are respectively $50 \mathrm{kN}, 55 \mathrm{kN}$ and $65 \mathrm{kN}$. The cracking loads of columns HC7, HC8 and HC9 are all $40 \mathrm{kN}$. That is as the axial compression ratio increases, the cracking load is also

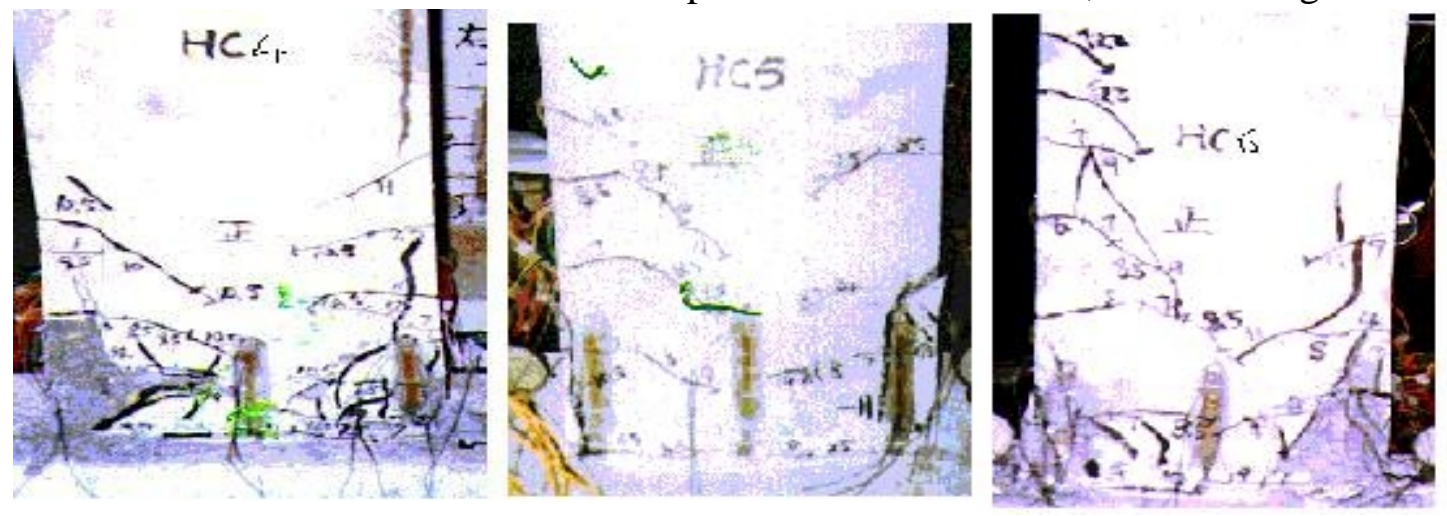

Fig.1 Damage picture of HC4 column Fig.2 Damage picture of HC5 column Fig.3 Damage picture of HC6 column
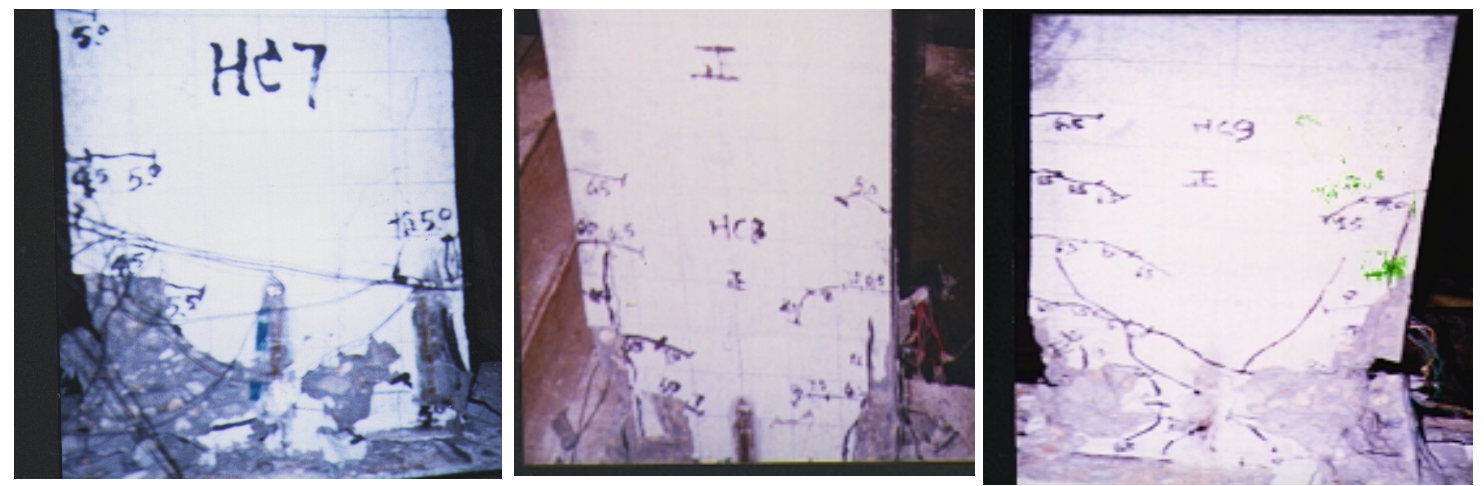

Fig.4 Damage picture of HC7 column Fig.5 Damage picture of HC8 column Fig.6 Damage picture of HC9 column

increased accordingly. Because the stirrup ratio and stirrup has no effect on the specimen cracking load, it can be considered that column cracking load and the axial load ratio have a certain relationship. A common law of development and the development of cracks of columns HC4、HC5 and HC6 are: With the increase of load, the original cracks in the column left and right edges of different height range continued to extend forward. The downmost crack has been extended to the neutral axis and the uppermost crack from the original horizontal crack extended down from the top; a plurality of horizontal cracks through and not through cross section appeared at different height positions in the left and right column and then they extended to the left of column face. Then a plurality of vertical cracks appeared at the left or right lower edge of front column, and several vertical cracks also appeared at left or right side of column, which indicates that the concrete begin spalling and the test specimen reach its ultimate load. With the repeated load, there appeared concrete peeling in the column about two root area(see Fig.1, 2, 3), the spalling concrete of column HC4, HC5 and HC6 aggravated and the development of cracks speeded up in order. The ruled of development and development cracks of columns HC7, HC8 and HC9 are: the original horizontal cracks appeared in the front or behind column continued, and at the same time there appeared new horizontal cracks at the upper part of the left or right side in the front or rear column; the development of the lower fracture is basically to the level of development; the development of the upper crack is the basic development from the top down. There appeared several vertical cracks at left or right edge in front or rear column and there also appeared a few vertical cracks in the column to the left or right, the concrete begin spalling and which indicates that the test specimen reach its ultimate load. With the repeated load, there appeared concrete peeling in the column about two root areas, the concrete of HC9 and HC8 column peeled severity and their crack development is also rapidly. When the HC7 column reached the ultimate load, starting repeated loading. Because of the less column reinforcement ratio and stirrup ratio, when repeated loading a cycle there appeared a huge burst of sound and the larger vertical displacement. The column occurred sudden bending 
brittle destruction. Because of bending failure, the cracks is very wide; spalling concrete is very serious; spalling of concrete is serious at the high $0 \sim 25 \mathrm{~cm}$ in the front left margin; through the lower level around the crack(see fig.4).

The column HC8 and HC9 had some severe spalling of concrete at column root; some concrete had thin shedding phenomenon; even some reinforced in the roots all exposed (see fig.5 and 6). High strength concrete frame column subjected to complex and is destroyed in the common effect of the axial

Tab 1 Schedule of main test results

\begin{tabular}{|c|c|c|c|c|c|c|c|c|c|c|c|c|c|c|c|c|}
\hline \multirow{3}{*}{$\begin{array}{l}\text { Item } \\
\text { Specim } \\
\text { en }\end{array}$} & \multirow{3}{*}{$\begin{array}{c}\text { Cube } \\
\text { strengt } \\
\mathrm{h} \\
\mathrm{f}_{\mathrm{cu}}\end{array}$} & \multirow{3}{*}{$\begin{array}{c}\text { The } \\
\text { actual } \\
\text { axial } \\
\text { compr } \\
\text { ession } \\
\text { ratio } n_{c}\end{array}$} & \multicolumn{6}{|c|}{ Cracking load and deformation } & \multicolumn{2}{|c|}{ Yield } & \multicolumn{2}{|c|}{$\begin{array}{c}\text { The maximum } \\
\text { load }\end{array}$} & \multicolumn{2}{|c|}{$\begin{array}{c}\text { The limit } \\
\text { deformation }\end{array}$} & \multirow{3}{*}{$\begin{array}{l}\text { Ductility } \\
\text { factor } \mu_{\mathrm{s}}\end{array}$} & \multirow{3}{*}{$\begin{array}{c}\text { Relative } \\
\text { limit angle } \\
\theta(\%)\end{array}$} \\
\hline & & & \multicolumn{2}{|c|}{$\mathrm{V}_{\mathrm{BC}}(\mathrm{kN})$} & \multicolumn{2}{|c|}{$\mathrm{V}_{\mathrm{SC}}(\mathrm{kN})$} & \multicolumn{2}{|c|}{$\mathrm{V}_{\mathrm{vd}} \mathrm{kN}$} & \multirow{2}{*}{$\begin{array}{c}\delta_{\mathrm{y}} \\
(\mathrm{mm})\end{array}$} & \multirow{2}{*}{$\begin{array}{c}\mathrm{V}_{\mathrm{y}} \\
(\mathrm{kN})\end{array}$} & \multirow{2}{*}{$\begin{array}{c}\mathrm{V}_{\mathrm{su}} \\
(\mathrm{kN})\end{array}$} & \multirow{2}{*}{$\begin{array}{c}\delta_{\mathrm{su}} \\
(\mathrm{mm})\end{array}$} & \multirow{2}{*}{$\begin{array}{c}\delta_{\mathrm{u}} \\
(\mathrm{mm} \\
)\end{array}$} & \multirow{2}{*}{$\begin{array}{c}\mathrm{V}_{\mathrm{u}} \\
(\mathrm{kN})\end{array}$} & & \\
\hline & & & le & ight & left & right & left & right & & & & & & & & \\
\hline $\mathrm{HC} 4$ & 59.53 & 0.433 & 50 & & & 80 & & & & & 108.1 & & 28.0 & & & \\
\hline HC5 & 59.53 & 0.495 & 55 & 6 & 80 & 70 & $\overline{105}$ & 100 & 8.5 & 7.76 & 109.01 & 13.8 & 23.5 & 92.70 & 8 & 0 \\
\hline HC6 & 59.53 & 0.577 & 70 & & & 75 & 110 & 105 & 10.4 & 93.74 & 108.08 & 13.8 & 23.4 & 91.13 & & \\
\hline HC7 & 59.53 & 495 & 45 & 40 & & 70 & 90 & 50 & 8.9 & 59.94 & 74.11 & 16.7 & 24.5 & 63.00 & 2.78 & .75 \\
\hline $\mathrm{HC} 8$ & 59.53 & 495 & 40 & 45 & 60 & 65 & 60 & 70 & 10.3 & 63.59 & 81.73 & 18.4 & 30.0 & 69.47 & 2.92 & .15 \\
\hline HC9 & 59.53 & 0.495 & 40 & 65 & 55 & 90 & 95 & 70 & 9.6 & 63.92 & 83.28 & 18.7 & 29.5 & 70.88 & 3.08 & 2.10 \\
\hline
\end{tabular}

Notes: $\mathrm{V}_{\mathrm{BC}}$ The horizontal force as bending fracture; $\mathrm{V}_{\mathrm{SC}}$ The horizontal force as the shear inclined cracks; $\mathrm{V}_{\mathrm{VC}}$ The horizontal force as vertical crack

force, shear force and bending moment. The failure mode of column HC4 HC6 mainly depends on the axial compression ratio, stirrup ratio (or the stirrup characteristic value of stirrup reinforcement), stirrup form, the content and strength of the longitudinal reinforcement. The design is due to the strong shear weak flexure, so the failure form is bending failure. From the test failure phenomenon can be seen: Column $\mathrm{HC}$, $\mathrm{HC} 8$ and $\mathrm{HC} 9$ also belong to the bending damage. The stirrup type of column $\mathrm{HC7}$ is the common rectangle hoop, and its stirrup ratio is less, so its ductility poorer than the columns $\mathrm{HC} 8$ and $\mathrm{HC} 9$ and there is a sudden brittle failure. The stirrup type of column $\mathrm{HC} 8$ and $\mathrm{HC} 9$ is composite band brace rectangular hoop and cross coupling and they have good ductility.

Experimental results. The main test data shown in Table 1.

The hysteretic curves and skeleton curves.The experiment of 6 high-strength concrete frame columns with high axial compression ratio under repeated load test was carried out at this test, and the hysteretic characteristics were studied. The test load displacement of the hysteretic curve and skeleton curve has the characteristics as follows:

(1) Literature [6] gives the typical hysteresis curves and skeleton curves under different axial compressive ratio and stirrup under different form. In case of high axial compression ratio, the decline of skeleton curve is steeper, the component lost large capacity, and energy dissipation ability is low ${ }^{[3]}$.

(2) With axial compression ratio of high strength concrete columns increases, the yield point is more and more no obvious, deformation capacity decrease. The results also indicate that when using a compound stirrup with certain volume reinforcement ratio, if axial compression ratio is not large, the reinforced plastic zone can be developed in a long range, even if the axial compression ratio is large, there is still a certain plastic section. So, the deformation capacity is improved obviously ${ }^{[5,6]}$.

(3) The experimental hysteretic curves show that horizontal bearing capacity supported positive loading is different that supported reverse loading. This produced difference has to do with the column initial state and the horizontal load of this difference before the horizontal load is applied and component protection layer of varying thickness on both sides also, and concerning the factors of construction quality ${ }^{[5]}$.

(4) Columns HC4, HC5 and HC6 have exactly the same reinforcement ratio, stirrup ratio, section size, concrete strength grade. Literature [6] gives the hysteretic curves under different axial compression ratios. It can see clearly that there is great influence of axial compression ratio on the ductility. With the decrease of axial compression ratio of the columns, the hysteretic curve is more and more become full, the cumulative hysteretic energy become more and more, the absorbed 
earthquake energy increases, the ductility also increases accordingly. From the hysteretic curves can be seen, the columns with rectangular cross brace under high axial compression ratio can still meet the seismic performance requirements.

\section{Conclusions}

(1) The columns took place flexural failure, and the degree of surface concrete shedding as failure of column has much to do with axial compression ratio, stirrup ratio and hoop reinforcement form. The surface concrete shedding of columns with high axial compression ratio and low hoop rate of the column drop more serious and those of columns with low axial compression ratio and high hoop rate drop slightly.

(2) With the decrease of axial compression ratio and stirrup ratio increases, the column hysteretic curve become increasingly full; the cumulative hysteretic energy become more and more big; the absorbed earthquake energy increases; the ductility also increases accordingly. Under cyclic loading, the skeleton curve of composite hoop column is long and gentle slope; its hysteretic curve is plump; its plastic deformation capacity is strong; because the side shift is too large, a damage was happened finally, which is bending ductility damage.

(3) Whether high or low strength concrete frame column, with the axial compression ratio increases, the ductility decreases. The ductility of ordinary concrete columns linearly decreases with axial compression ratio increases, and ductility and axial compression ratio is basically linear relation; the ductility of high strength concrete frame columns decreases nonlinearly with axial compression ratio increases, and with the axial compression ratio decreases, the ductility amplitude reduces more and more.

(4) With its stirrup ratios increase, the ductility of high strength concrete columns increases. The ductility of the columns with cross coupling composite hoop is better than that of the columns with rectangle hoop, and the ductility of column with rectangle hoop is a little poor.

\section{References}

[1]Priyan A . Mendis . Behavior of Slender High-Strength Concrete Columns[J] . ACI Structural Journal , November-December 2000 .

[2]Frédéric Légeron and Patrick Paultre . Behavior of High-Strength Concrete Column under Cyclic Flexure and Constant Axial[J] . ACI Structural Journal , July-August 2000 , 591-601

[3]Wang Qingxiang, Zhao Guofan, Lin liyan. Experimental study of high strength concrete column ductility [J]. Journal of building structures, 1995, 16(4), $22 \sim 31$.

[4]Code for design of concrete structure ( GBJ10-2011 ) [M]. China Building Industry Press, 2011.

[5]Guojun Zhang, Boquan Liu, Guoliang Bai, Jianxin Liu. Experimental Study on Seismic Behavior of High Strength Reinforced Concrete Frame Columns with High Axial Compression Ratios [J]. Structural Engineering and Mechanics , 2009, 33(5): 653-656.

[6]ZHANG Guojun. Experimental research on seismic behaviors of high-strength concrete frame columns[R]. Postdoctoral Come-out-Station Reports of Tongji University, Shanghai: Tongji University, 2006.( in Chinese) 